\section{Oncocytoma of the upper conjunctival fornix}

\section{Zaina Al-Mohtaseb, Seongmu Lee, Michael T. Yen \\ Cullen Eye Institute, Department of Ophthalmology, Baylor College of Medicine, Houston, Texas, USA}

\begin{abstract}
Oncocytomas are tumors characterized by large, eosinophilic epithelial cells with abundant mitochondria that form ductular or glandular spaces. While these tumors have been described in other organs, those of the ocular adnexa occur infrequently, with the caruncle being the most common site of involvement. Conjunctival oncocytomas are extremely rare and are believed to arise from the ductal elements of the lacrimal gland proper and the accessory lacrimal glands of the conjunctiva. We describe the clinical and histological features of a case of an oncocytoma presenting as an atypically located superior fornix mass in a 78-yearold female, with a review of the literature.
\end{abstract}

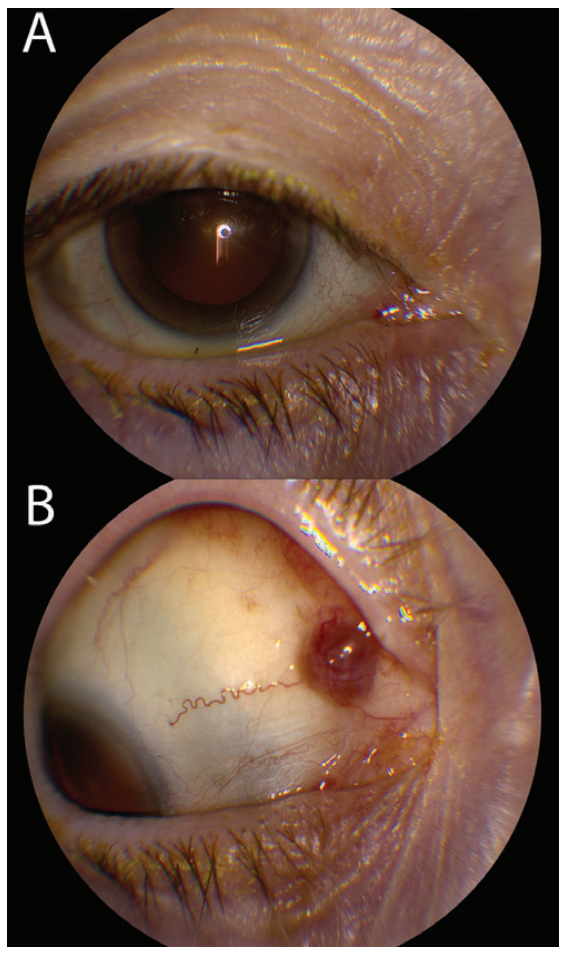

Figure 1. Anterior segment image revealing a round, well-circumscribed, mobile, elevated red lesion measuring $3.0 \times 3.0 \times 3.0$ $\mathrm{mm}$ in the bulbar conjunctiva of the superior fornix concealed under the eyelid.

\section{Case Report}

Oncocytomas are tumors characterized by large, eosinophilic epithelial cells with abundant mitochondria that form ductular or glandular spaces. While these tumors have been described in many organs including the salivary, thyroid, adrenal glands, and kidneys, those of the ocular adnexa are uncommon and are believed to arise from metaplasia of the ducts of the lacrimal gland epithelium. The caruncle is the most common site of involvement, representing approximately $3 \%$ of tumors in this region. ${ }^{1-3}$ Oncocytomas of the conjunctiva, however, are extremely rare.$^{1-6} \mathrm{We}$ report a case of an atypically located conjunctival oncocytoma and review the literature.

A 78-year-old female was referred for evaluation of fornix lesion. Examination revealed a round, well-circumscribed, mobile, elevated red lesion measuring $3.0 \times 3.0 \times 3.0 \mathrm{~mm}$ in the bulbar conjunctiva of the superior fornix near the right medial canthus, concealed under the eyelid (Figure 1). Histological examination showed a well-demarcated mass composed of tubular epithelial structures with a central lumen (Figure 2). The cells showed uniform round/oval nuclei surrounding central lumina and prominent basement membrane. The cytoplasm of the epithelial cells contained prominent eosinophilic granules that stained with Masson trichrome. The luminal border of the tubules also stained with PAS and colloidal iron. A diagnosis of oncocytoma was made.

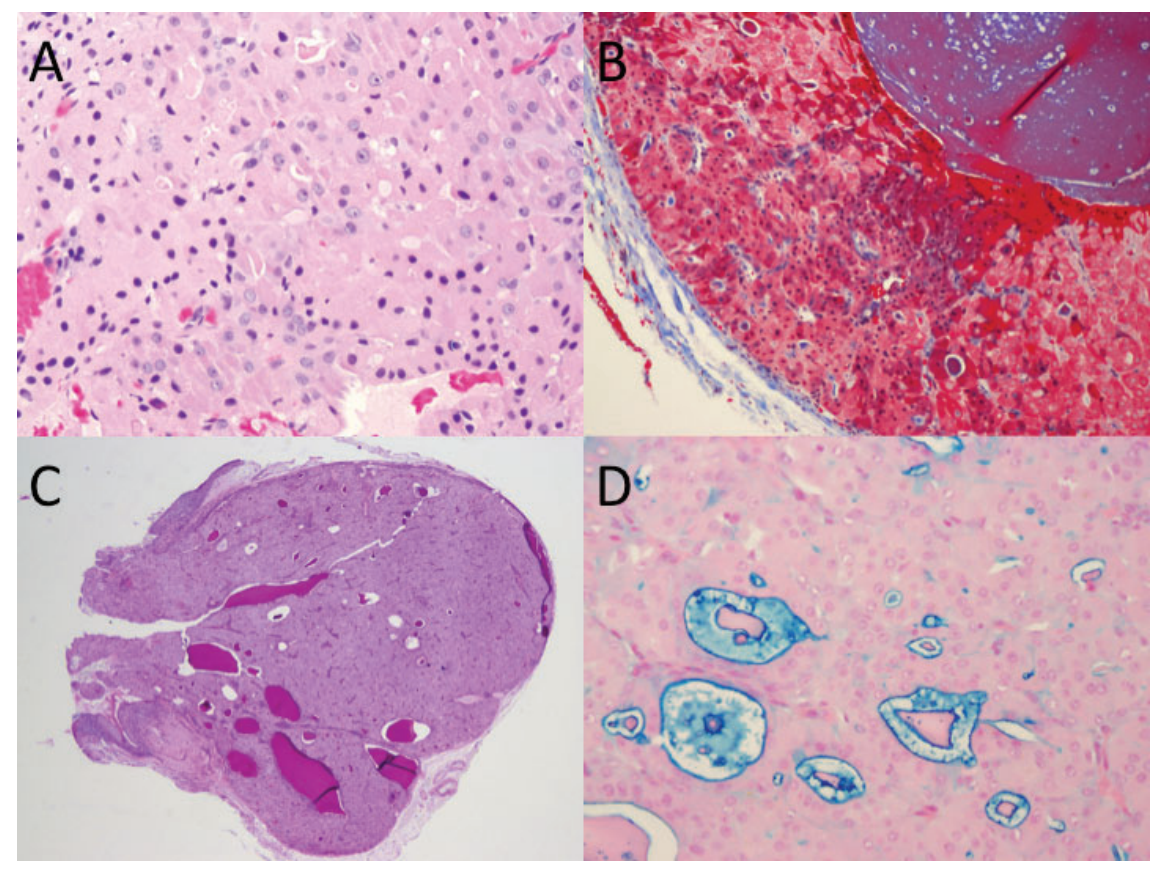

Figure 2. A) Histological examination showed a well-demarcated mass composed of tubular epithelial structures with a central lumen consistent with oncocytoma. B) The cytoplasm of the epithelial cells contained prominent eosinophilic granules that stained with Masson trichrome. The luminal border of the tubules also stained with C) PAS and D) Masson trichromal iron.
colloidal
Correspondence: Seongmu Lee, Cullen Eye Institute, Department of Ophthalmology, Baylor College of Medicine, 6565 Fannin NC-205, Houston, Texas 77030, USA.

Tel. +1.713.798-3231 - Fax: +1.713.798.8739.

E-mail: SeongL@bcm.edu

Key words: oncocytoma, oxyphil adenoma, conjunctival, lacrimal, caruncle.

Contributions: the authors contributed equally.

Conflict of interest: the authors report no conflicts of interest.

Funding: supported in part by an unrestricted educational grant from Research to Prevent Blindness, Inc. (New York, NY).

Received for publication: 22 June 2011. Accepted for publication: 22 August 2011.

This work is licensed under a Creative Commons Attribution NonCommercial 3.0 License (CC BYNC 3.0).

(C) Copyright Z. Al-Mohtaseb et al., 2011

Eye Reports 2011; 1:e

doi:10.4081/eye.2011.e7

\section{Discussion}

Oncocytomas of the ocular adnexa are uncommon and have been described in the
Licensee PAGEPress, Italy

rior fornix concealed under the eyelid. 
caruncle, lacrimal sac, lacrimal gland, and accessory glands of Krause. ${ }^{3,4}$ Conjunctival oncocytomas are extremely rare..$^{1-5}$ The tumor location in the conjunctival fornix in this case is particularly atypical. Of the reported cases in the published English literature, the average age was 68 -years, and $60 \%$ were female. The duration of symptoms ranged from two months to five years, with no evidence of recurrence reported after excision (Table 1). ${ }^{1-5,7-8}$

Clinically, oncocytomas have been described as red-brown or yellow-tan lesions that are elevated and at times lobulated or cystic. Histopathologically, these tumors are characterized by a proliferation of large, uniform, polygonal epithelial cells that exhibit abundant, fine granular eosinophilic cytoplasm and contain dark round to ovoid paracentral nuclei. The cytoplasm contains dark granules that are positive for modified phosphotungstic acidhaematoxylin and immunostain with monoclonal antimitochondrial antibodies due to the high density of mitochondria. ${ }^{1}$ The oncocytes form solid cords and tubular structures that occasionally display papillary infoldings and have a characteristic absence of inflammatory cells. In some areas, the tubules form large cystic spaces, which contain a seromucinous material that is periodic acid schiff and alcianblue positive., ${ }^{3,6}$

Many authors believe that oncocytomas arise from age-related oncocytic metaplasia of ducts and acinar cells of the accessory lacrimal glands of the ocular adnexa, while others suggest oncocytic transformation of the caruncular surface and conjunctival epithelium as the site of origin., ${ }^{1,36}$ In a more recent study, Ostergaard et al. examined the cytokeratin profile of oncocytic lesions of the ophthalmic region to investigate the origin of these tumors. The authors reported that oncocytomas of the ocular adnexa demonstrated a profile similar to that of the lacrimal gland proper and the accessory lacrimal gland duct elements, and that all lesions showed a similar expression pattern irrespective of histological differentiation, suggesting that oncocytic metaplasia, hyperplasia, and oncocytoma may represent the same type of lesion in different stages of development. ${ }^{1}$

In summary, oncocytomas of the conjunctiva are benign epithelial tumors most likely arising from ductal elements of the lacrimal gland proper and accessory lacrimal glands of the conjunctiva and may present in the conjunctival fornix.

\section{References}

1. Ostergaard J, Prause JU, Heegaard S. Oncocytic lesions of the ophthalmic region: a clinicopathological study with 
emphasis on cytokeratin expression. Acta Ophthalmol 2011;89:263-7.

2. Kurli M, Finger PT, Garcia JP Jr, Schneider S. Peribulbar oncocytoma: high-frequency ultrasound with histopathologic correlation. Ophthalmic Surg Lasers Imaging 2006;37:154-6.

3. Biggs SL, Font RL. Oncocytic lesions of the caruncle and other ocular adnexa. Arch
Ophthalmol 1977;95:474-8.

4. Pecorella I, Garner A. Ostensible oncocytoma of accessory lacrimal glands. Histopathology 1997;30:264-70.

5. Grossniklaus HE, Green WR, Luckenbach $\mathrm{M}$, Chan CC. Conjunctival lesions in adults: A clinical and histopathologic review. Cornea 1987;6:78-116.

6. Rennie IG. Oncocytomas (oxyphil adeno- mas) of the lacrimal caruncle. $\mathrm{Br} \mathrm{J}$ Ophthalmol 1980;64:935-9.

7. Reidel K, Stefani FH, Kampik A. Oncocytoma of the ocular adnexa. Klin Monatsbl Augenheilkd 1983;182:544-8.

8. Spraul CW, Lang GK. Oncocytoma of the conjunctiva. Klin Monbl Augenheilkd 1996;209:176-7. 